УДК 543.544:665.44

\title{
ИЗМЕНЕНИЕ АНТИОКСИДАНТНОЙ АКТИВНОСТИ ГУМИНОВЫХ И ФУЛЬВОКИСЛОТ В ПРОЦЕССЕ ХРАНЕНИЯ
}

\author{
(ㄱ С.Г. Маслов* , С.А. Кусмауль, О.А. Воронова, Е.И. Короткова
}

\begin{abstract}
Национальный исследовательский Томский политехнический университет, пр. Ленина, 30, Томск, 634050 (Россия), e-mail:maslovsg@tpu.ru
\end{abstract}

\begin{abstract}
Методом катодной вольтамперометрии исследовано изменение антиоксидантной активности гуминовых кислот, выделенных из двух видов торфа, разной степени разложения. Показано, что при хранении в течение года их антиоксидантная активность увеличивается.

Ключевые слова: торф, гуминовые кислоты, фульвокислоты, хранение, антиоксидантная активность, изменение.

Работа выполнена при финансовой поддержке в рамках Федеральной целевой программы «Научнье и научно-педагогические кадры инновачионной России» на 2009-2013 годы госконтракта № 14.740.11.1369 и соглашения № 14.B37.21.0811.
\end{abstract}

\section{Введение}

В настоящее время известен целый ряд химических соединений, существенно стимулирующих процессы роста живых организмов и способствующих повышению урожая сельскохозяйственных культур и продуктивности животных [1]. Так, например, результаты исследований показывают, что применение гуминовых стимуляторов роста (нитрогуматы аммония) не только повышает скорость роста животных организмов, но и изменяет баланс расхода питательных веществ, увеличивая ту его часть, которая используется для накопления биомассы организмов. Это дает основание для получения значительного экономического эффекта при использовании нитрогуминовых стимуляторов роста в процессе выращивания различных сельскохозяйственных животных.

Известно действие препараторов торфа на поведение и выживаемость животных в экстремальных условиях. Группа ученых из Калининского медицинского университета провела сравнительное исследование фармакологических свойств биологически активных веществ, полученных из торфа: нитрогумата ам-

Маслов Станислав Григорьевич - доцент кафедры химической технологии топлива и химической кибернетики Института природных ресурсов, кандидат технических наук, старший научный сотрудник, тел.: (3822) 56-46-08, e-mail: maslovsg@tpu.ru Кусмауль Светлана Алексеевна - инженер кафедры физической и аналитической химии Института природных ресурсов, e-mail: mlk@tpu.ru

Воронова Олеся Александровна - ассистент кафедры физической и аналитической химии Института природных ресурсов; кандидат химических наук, e-mail: oaa@tpu.ru

Короткова Елена Ивановна - заместитель проректорадиректора по науке и инновационному развитию Института природных ресурсов, доктор химических наук, профессор, тел.: (3822) 56-43-20, e-mail: eikor@mail.ru мония (НГА) и торфота [2].

Данные опыта показали, что при экстремальных воздействиях на организм (гипоксия или изнуряющая физическая нагрузка) НГА повышает защитные силы организма. В зависимости от дозы и способа введения вещества НГА может повышать или угнетать сопротивляемость животных к действию неблагоприятных факторов. При оптимальном подборе дозы НГА и способа его назначения можно значительно увеличить выносливость организма к максимальной физической нагрузке.

Во ВНИИТП разработан способ химической обработки верхового торфа низкой степени разложе-

\footnotetext{
* Автор, с которым следует вести переписку
} 
ния реагентами щелочного характера и небелковыми азотистыми соединениями, в частности мочевиной, позволяющий при пропаривании активизировать биологически активные вещества торфа и переводить углеводный комплекс в легкоусвояемое, доступное организму животного состояние [3].

Важнейшей задачей сельскохозяйственной науки является также разработка и внедрение методов повышения эффективности молочного животноводства. Особое значение имеет подобный подход для коров, находящихся в «критическом» перинатальном периоде онтогенеза - состояниях глубокой стельности, отела и начала лактации.

Известно, что в данных состояниях у животных имеют место выраженные изменения гормонального гомеостаза, резко возрастают энергетические потребности организма, в связи с чем происходят глубокие изменения жирового и углеводного метаболизма, следствием которых являются окислительный стресс, дисфункция и жировая инфильтрация печени, кетоз и кетоацидоз.

Целесообразным и научно обоснованным является обогащение кормов субстанциями природного происхождения, характеризующимися широким спектром регуляторных эффектов, низкой токсичностью, отсутствием продуктов метаболизма, негативно влияющих на человека. Положительные качества данных соединений определяют их соответствие современным требованиям и тенденциям производства экологически чистых продуктов. В молочном животноводстве применение подобных средств актуально не только для повышения резистентности животных, но и для улучшения качественных и количественных характеристик конечной продукции - молока.

В СибНИИСХиТ Россельхозакадемии разработана кормовая добавка на основе гуминовых соединений торфа - Гумитон (Per. № ПВР-2-10.8/02357). На базе сельскохозяйственно-производственного кооператива «Нелюбино» Томской области проведена работа по изучению влияния добавки на некоторые показатели метаболизма глубокостельных коров молочного направления, оценке ее эффективности в качестве средства профилактики патологических отелов и послеродовых осложнений, а также повышения продуктивности животных.

Суммарный экономический эффект, полученный в опытной группе в результате проведения лечебно-профилактических мероприятий, составил в расчете на 1 руб. затрат на Гумитон 7,39 руб. (\$0,25) на одно животное.

У коров, получавших Гумитон, выявлены признаки более ранней нормализации явлений нарушений функции желчевыделительной системы, что свидетельствует о гепатопротекторном эффекте добавки, а также, через 1 месяц после отела уровень антиоксидантной активности плазмы крови превышал контрольный на 23\%. Полученные результаты свидетельствуют о том, что применение Гумитона оказывает профилактическое воздействие по отношению к развитию функциональных нарушений печени у коров, способствует регуляции у них антиоксидантного статуса и снижению частоты развития патологий отелов и послеродовых осложнений.

Таким образом, применение кормовой добавки Гумитон у стельных и лактирующих высокоудойных коров является высокоэффективным и экономически выгодным способом профилактики у них патологических отелов и послеродовых осложнений, а также повышения продуктивности. Эффект добавки связан с ее способностью регулировать нарушения метаболизма, характерные для животных в критический период глубокой стельности, отелов и лактации, оказывать нормализующее воздействие на функцию печени и стимулировать показатели клеточного и гуморального иммунитета [4].

Известно, что гуминовые и фульвокислоты являются антиоксидантами [6], но изменение антиоксидантных свойств этих веществ в процессе хранения не проводилось.

Цель данного исследования - анализ изменения антиоксидантной активности гуминовых и фульвокислот в процессе хранения.

Для этого использовали методику катодной вольтамперометрии [6].

\section{Экспериментальная часть}

Для исследования использовали гуминовые и фульвокислоты, выделенные методом Института торфа [5], из торфов, характеристика которых представлена в таблице 1.

Методика определения антиоксидантной активности [6]. Экспериментальные исследования в данной работе проводились на вольтамперометрическом анализаторе антиоксидантной активности «Анализатор AOA» (OOO «НПП Полиант» г. Томск, Россия) в комплекте с персональным компьютером. 
Таблица 1. Характеристика исходных торфов

\begin{tabular}{c|c|c|c|c}
\hline \multirow{2}{*}{$\begin{array}{c}\text { Шифр } \\
\text { пробы }\end{array}$} & \multicolumn{2}{|c|}{ Ботанический состав } & Тип и вид торфа & $\begin{array}{c}\text { Степень } \\
\text { разложения, \% }\end{array}$ \\
\cline { 2 - 3 } 9333.2 & растение-торфообразователь & содержание, $\%$ & верховой & 5 \\
& сфагнум-фускум & 80 & сфагнум-фускум & \\
& сфагнум-ангустифолиум & 5 & & 15 \\
& сфагнум-магелланикум & 10 & магелланикум & \\
& неопределенный остаток & 5 & (медиум-торф) & \\
& сфагнум-магелланикум & 75 & & \\
& сфагнум-ангустифолиум & 15 & & \\
& сфагнум-балтикум & 5 & & \\
& пушица & 5 &
\end{tabular}

Приборы, ячейки, электроды, реактивы и растворыл. Анализатор АОА предназначен для автоматизированного анализа антиоксидантной активности методом вольтамперометрии проб природных и техногенных объектов, лекарственных препаратов, биологических объектов, пищевых продуктов, напитков и т.п. Работает в простом режиме с постоянно-токовой формой развертки поляризующего напряжения. Особенности анализатора: одна электрохимическая ячейка с возможностью работы в трехэлектродном режиме, перемешивание раствора путем стабилизированной вибрации индикаторного электрода; электрохимический способ нанесения тонкой пленки ртути на серебряную подложку индикаторного электрода; надежное и удобное крепление электродов, исключающее контакт оператора с рабочей поверхностью электрода; программный способ реализации анализа. Анализатор работает в комплексе с персональным компьютером. Наиболее важные технические характеристики анализатора: диапазон поляризующего напряжения от 0,0 до -1,0 В, диапазон измеряемого тока от 0 до 3.0 мА, воспроизводимость аналитических сигналов 10-15\%; продолжительность анализа проб 30 мин.

Антиоксидантная активность исследуемых веществ определялась по следующей методике: снимались вольтамперограммы тока ЭВ О 2 в отсутствие исследуемого вещества (фоновая кривая) по описанному выше способу. При отсутствии посторонних пиков фоновый раствор считался чистым. Затем в ячейку добавлялось исследуемое вещество. Отбор образца брался по следующему алгоритму: для исследования из каждого раствора брали аликвоту 0,2 мл, снималась катодная вольтамперограмма ЭВ О 2 при тех же условиях. Измерения повторялись не менее 3 раз через определенный промежуток времени и каждый раз оценивалось значение предельного тока ЭВ $\mathrm{O}_{2}$.

Уменьшение тока ЭВ $\mathrm{O}_{2}$ по своему абсолютному значению свидетельствует о том, что антиоксиданты реагируют с кислородом или его активными радикалами в исследуемом растворе, сами окисляясь при этом. Степень уменьшения тока ЭВ $\mathrm{O}_{2}$ являлась показателем антиоксидантной активности исследуемых веществ.

\section{Обсуждение результатов}

Основными носителями биологической активности в торфе являются гуминовые кислоты (ГК). Их физиологическое действие связывают с влиянием на интенсивность фотосинтеза, активизацию кислородного, белкового, углеводного обмена растений. Проводятся попытки связать их биологическую активность с реакционной способностью по отношению к процессу ЭВ $\mathrm{O}_{2}$, со структурными особенностями препаратов, например соотношением в молекуле ГК гидрофильных и гидрофобных составляющих. Для изучения тканевого дыхания растений ряд исследователей использовали принцип амперометрического анализа кислорода. Однако полученные разными авторами результаты не всегда согласуются между собой из-за неоднородности химического состава и свойств ГК, что в значительной мере может зависеть от исходного сырья, способов получения, очистки препаратов и методов оценки их биологической активности.

ГК, представляющие собой полисопряженные системы с широким спектром функциональных групп, характеризуются высокой реакционной способностью и восстановительными свойствами.

Для оценки влияния гуминовых препаратов на процесс ЭВ $\mathrm{O}_{2}$ рассмотрены зависимости предельного тока ЭВ $\mathrm{O}_{2}$ от характеристики торфов. Для всех исследуемых ГК получены однотипные вольтамперограммы. Наблюдалось увеличение катодного тока ЭВ $\mathrm{O}_{2}$ при добавлении ГК и сдвиг потенциала в отрицательную область, что свидетельствует о проявлении активности гуминовых препаратов по отношению к данному процессу по механизму наличия последующей реакции диспропорционирования и частичной регенерации молекулярного кислорода в присутствии ГК. 
Полученные нами данные представлены в таблице 2. Показатель антиоксидантной активности исследуемых образцов определяли по относительному увеличению тока ЭВ $\mathrm{O}_{2}$, используя емкостный критерий.

В процессе проведения работы были выделены образцы гуминовых и фульвокислот, проведены исследования их антиоксидантных свойств и проанализировано изменение антиоксидантных свойств гуминовых и фульвокислот в процессе хранения.

Исследованные образцы условно подразделялись на три группы: ГК-1 и ФК-1 (выделенные из ряда торфов Васюганского месторождения); ГК-2, ФК-2 (шифр пробы - 933.2) и ГК-3, ФК-3 (шифр пробы 397-М1).

Таким образом, изучено влияние гуматов на процесс электровосстановления кислорода.

Наибольшей антиоксидантной активностью обладают образцы ГК1 и ФК1 (выделенные из ряда торфов Васюганского месторождения), наименьшей - ГКЗ и ФКЗ.

Такие изменения в поведении ГК и ФК в процессе ЭВ $\mathrm{O}_{2}$, по-видимому, связаны с разной молекулярной структурой, зависящей от типа сырья.

Гуматы представляют собой комплексы металлов. Существует мнение, что катион-гумусные комплексы могут играть роль инициаторов или ингибиторов различных процессов в природе. Так, перенос кислорода в живых организмах происходит за счет связывания его с макроциклическим комплексом железа, основная роль которого как катализатора заключается в ослаблении связи О-О, ее разрыхлении в процессе связывания молекулярного кислорода с ионом металла. Очевидно, особенности молекулярного строения органической части ГК, включающих карбоксильные группы, фенольные гидроксилы и хиноидные металлокомплексы, в большей степени, определяют их поведение в процессе ЭВ О 2 . Карбоксильные группы и фенольные гидроксилы способны к ионизации, создавая на поверхности макромолекул ГК отрицательный заряд, что широко используют при электрофорезе для оценки эффективности их фракционирования. Хиноидные структуры определяют протекание окислительно-восстановительных реакций и смещение равновесия в системе хинон-семихинон-гидрохинон. Окисленные хиноидные и восстановленные гидрохиноидные ароматические фрагменты могут образовывать прочные диамагнитные комплексы и переходить в парамагнитное состояние при изменениях окислительно-восстановительных условий среды. В восстановительных условиях такие комплексы, принимая пару электронов, сохраняют парамагнетизм, а в окислительных условиях в присутствии кислорода переходят обратно в исходное состояние.

Таблица 2. Суммарная антиоксидантная активность исходных образцов

\begin{tabular}{|c|c|c|c|c|c|c|c|c|c|c|c|}
\hline \multirow{3}{*}{ 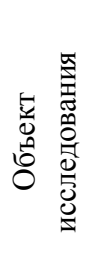 } & \multicolumn{11}{|c|}{ Изменение антиоксидантной активности в процессе хранения } \\
\hline & \multicolumn{11}{|c|}{ Даты исследования } \\
\hline & $\begin{array}{l}= \\
\overline{8} \\
\stackrel{2}{0}\end{array}$ & 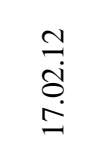 &  & 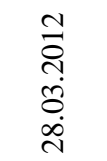 & 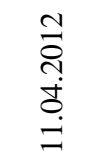 & 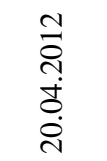 & $\begin{array}{l}\stackrel{\sim}{1} \\
\dot{J} \\
\stackrel{0}{0}\end{array}$ & 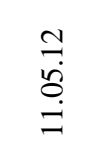 & 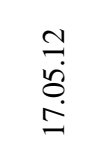 & 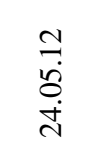 & 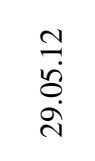 \\
\hline \multirow[t]{3}{*}{$\Gamma \mathrm{\Gamma}-1$} & 3,1245 & 3,8278 & 4,2378 & 4,7228 & 5,0216 & 5,4685 & 5,8964 & 6,0342 & 6,2865 & 6,4876 & 6,6278 \\
\hline & 3,2456 & 3,7554 & 3,9856 & 4,0024 & 4,9563 & 5,3984 & 5,7945 & 6,0076 & 6,3976 & 6,7896 & 6,8943 \\
\hline & 3,1398 & 3,8246 & 4,2068 & 4,5341 & 5,0052 & 5,4896 & 5,8923 & 6,0289 & 6,3564 & 6,3286 & 6,7432 \\
\hline \multirow[t]{3}{*}{ ГК -2} & - & - & - & 3,2842 & 3,6984 & 3,9067 & 4,2867 & 4,5876 & 4,8453 & 5,0564 & 5,2376 \\
\hline & & & & 3,0157 & 3,5983 & 3,8693 & 4,1945 & 4,5342 & 4,8795 & 5,1267 & 5,2543 \\
\hline & & & & 3,4529 & 3,8691 & 3,9681 & 4,3076 & 4,6005 & 4,9023 & 5,1987 & 5,3654 \\
\hline \multirow[t]{3}{*}{ ГК-3 } & - & - & - & 2,9382 & 3,0021 & 3,3894 & 3,6954 & 3,9654 & 4,2453 & 4,4654 & 4,5897 \\
\hline & & & & 3,0759 & 3,2845 & 3,5058 & 3,8578 & 4,0043 & 4,3005 & 4,6549 & 4,7453 \\
\hline & & & & 2,8954 & 3,0067 & 3,3957 & 3,7945 & 3,9864 & 4,2764 & 4,4866 & 4,5897 \\
\hline \multirow[t]{3}{*}{$\Phi К-1$} & 2,2343 & 2,6894 & 3,0216 & 3,3185 & 3,5623 & 3,8945 & 4,1278 & 4,4543 & 4,7498 & 4,9845 & 5,0045 \\
\hline & 2,3452 & 2,7957 & 3,0425 & 3,4148 & 3,7534 & 3,9934 & 4,2895 & 4,5214 & 4,8543 & 4,9943 & 5,0154 \\
\hline & 2,4598 & 2,9532 & 3,1267 & 3,7987 & 3,8345 & 4,0045 & 4,3694 & 4,6023 & 4,8904 & 4,9267 & 5,0067 \\
\hline \multirow[t]{3}{*}{$\Phi К-2$} & - & - & - & 2,7349 & 2,8634 & 3,0034 & 3,3856 & 3,6052 & 3,9453 & 4,0034 & 4,1876 \\
\hline & & & & 2,7020 & 2,8512 & 2,9567 & 3,2997 & 3,5195 & 3,8856 & 3,9876 & 4,0876 \\
\hline & & & & 2,7529 & 2,9002 & 3,1298 & 3,3967 & 3,6423 & 3,9786 & 4,0096 & 4,1587 \\
\hline \multirow[t]{3}{*}{ ФК-3 } & - & - & - & 1,0477 & 1,3687 & 1,5798 & 1,8632 & 2,1256 & 2,4563 & 2,5893 & 2,6564 \\
\hline & & & & 1,1673 & 1,4563 & 1,7487 & 2,0045 & 2,2006 & 2,5004 & 2,6897 & 2,7965 \\
\hline & & & & 1,0587 & 1,4387 & 1,7946 & 2,1065 & 2,2854 & 2,5765 & 2,6980 & 2,7976 \\
\hline
\end{tabular}


При влиянии данных веществ на процесс ЭВ $\mathrm{O}_{2}$ наблюдается увеличение тока ЭВ $\mathrm{O}_{2}$ и сдвиг потенциала волны в отрицательную область, что характеризует наличие последующей химической реакции диспропорционирования, в результате которой происходит частичная регенерация деполяризатора (молекулярного кислорода) по следующему механизму:

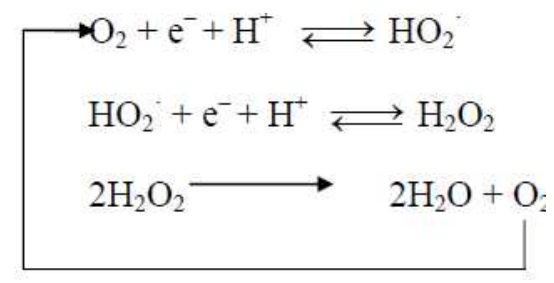

Предполагается, что данная каталитическая активность обусловлена эффектом взаимодействия $\mathrm{O}_{2}$ с центральным ионом металла. Очевидно, в данном случае ион металла, взаимодействуя с кислородом на поверхности электрода, оказывает каталитическое влияние на данный процесс. Об эффекте взаимодействия и каталитическом влиянии говорит и сдвиг потенциала волны ЭВ $\mathrm{O}_{2}$ в отрицательную область при добавлении образцов в раствор.

В данной работе в качестве сравнения антиоксидантных свойств образцов ГК и ФК с исследованиями лаборатории кафедры физической и аналитической химии ИПР (лаборатория по контролю качества БАД) использовали общеизвестные вещества (хлорофилл-каротиновые пасты, фталоцианины) с целью сравнения полученных нами результатов.

Наибольший интерес вызывают такие компоненты хвои, как хлорофилл и каротиноиды. Хлорофилл широко распространен в природе, содержится во всех фотосинтезирующих организмах.

Исследовалось влияние хлорофилл-каротиновой пасты (ХКП), полученной из хвои сосны по методике, описанной выше, на процесс ЭВ О 2 . При добавлении ХКП ток ЭВ О 2 возрастал пропорционально концентрации данного образца в растворе. Увеличение тока свидетельствует о том, что ХКП проявляет антиоксидантную активность по отношению к процессу ЭВ $\mathrm{O}_{2}$.

Показано, что хлорофилл, как и большинство порфиринов и их аналогов, обладает неплохой антиоксидантной активностью. Предполагается, что это обусловлено эффектом взаимодействия $\mathrm{O}_{2}$ с центральным ионом металла в порфириновом кольце молекулы хлорофилла. Ион $\mathrm{Mg}^{2+}$, находясь в центре порфиринового кольца, взаимодействуя с кислородом на поверхности электрода, оказывает каталитическое влияние на данный процесс. О чем свидетельствует и сдвиг потенциала волны ЭВ О 2 в отрицательную область при добавлении ХКП в раствор, что аналогично в случае с ГК.

При сравнительном анализе полученных в данной работе результатов определения антиоксидантной активности гуминовых и фульвокислот (см. табл. 2) с фталоцианинами металлов и хлорофилл-каротиновой пасты (см. табл. 3) было установлено, что по сравнению с фталоцианинами металлов гуминовые и фульвокислоты проявляют большую активность. Так, например, активность фталоцианина никеля в 3 раза меньше образца ГК-1. В случае хлорофилл-каротиновой пасты ее антиоксидантная активность почти в 4,5 раза ниже образца ГК-1. В целом же исследованные ГК и ФК проявляют схожую антиоксидантную активность с изученными ранее веществами, в частности фталоцианинами металлов и хлорофилл-каротиновыми пастами.

Основной целью данной работы являлся анализ изменения антиоксидантной активности ГК и ФК в процессе хранения. Анализируя полученные результаты, можно сделать следующие выводы:

1. Изучено влияние гуминовых и фульвокислот на процесс электровосстановления кислорода. Анализ полученных данных показал, что результаты исследований образцов ГК-2 и ГК-3 незначительно отличаются, а результаты образцов ФК-2 и ФК-3 отличаются в 2 раза. В результате эксперимента установлено, что образец ГК-1 проявляет большую активность, которая превышает активность образца ФК-3 в три раза. Такие существенные изменения в поведении ГК и ФК в процессе электровосстановления кислорода, по-видимому, связаны с разной молекулярной структу-

Таблица 3. Результаты определения антиоксидантной активности фталоцианинов металлов и хлорофилл-каротиновой пасты

\begin{tabular}{l|c}
\hline \multicolumn{1}{c|}{ Название } & $K$, мл/мг \\
\hline Фталоцианин хрома & $4,37 \pm 0,22$ \\
Фталоцианин кобальта & $3,56 \pm 0,18$ \\
Фталоцианин никеля & $2,02 \pm 0,12$ \\
Хлорофилл-каротиновая паста & $1,49 \pm 0,12$ \\
\hline
\end{tabular}
рой, зависящей от типа исходного сырья. 
Показано, что все исследованные гуминовые вещества обладают достаточно высокой антиоксидантной активностью. Предполагается, что данная антиоксидантная активность обусловлена эффектом взаимодействия кислорода с центральным ионом металла. Очевидно, в данном случае ион металла, взаимодействуя с кислородом на поверхности электрода, оказывает каталитическое влияние на данный процесс. Об эффекте взаимодействия и каталитическом влиянии говорит и сдвиг потенциала волны электровосстановления кислорода в отрицательную область при добавлении образцов в раствор.

2. Установлено, что антиоксидантная активность гуминовых кислот в процессе хранения увеличивается. Анализ результатов показал, что антиоксидантная активность всех образцов увеличивается в 2 раза, за исключением образцов ГК-2 и ГК-3, результаты которых увеличиваются в 1,5 раза.

3. Установлено, что антиоксидантная активность фульвокислот в процессе хранения увеличивается. Анализ результатов показал, что антиоксидантная активность всех образцов увеличивается в 2 раза, за исключением образца ФК-1. Здесь произошло увеличение в 2,5 раза.

\section{Заключение}

Многие биохимические реакции в организме протекают с образованием и участием свободных радикалов. Их концентрация тонко регулируется сложными физико-химическими механизмами, нарушение которых может привести к возникновению окислительного стресса. Поэтому все возрастающую роль играет постоянный контроль за содержанием антиоксидантов в биологических объектах. Все возрастающее использование антиоксидантов требует дальнейшего развития методов их исследования, как индивидуальных, так и в составе сложных смесей.

В результате проведенных исследований установлено влияние гуминовых и фульвокислот на процесс электровосстановления кислорода. Показано, что все исследованные гуминовые препараты обладают достаточно высокой каталитической активностью, которая зависит от исходного типа торфа. Изучено влияние гуминовых и фульвокислот на процесс электровосстановления кислорода. Анализ полученных данных показал, что результаты исследований образцов ГК-2 и ГК-3 незначительно отличаются, а результаты образцов ФК-2 и ФК-3 отличаются в 2 раза. В результате эксперимента установлено, что образец ГК-1 проявляет большую активность, которая превышает активность образца ФК-3 в 3 раза. Такие существенные изменения в поведении ГК и ФК в процессе электровосстановления кислорода, по-видимому, связаны с разной молекулярной структурой, зависящей от типа исходного сырья.

Показано, что все исследованные гуминовые вещества обладают достаточно высокой антиоксидантной активностью. Предполагается, что данная антиоксидантная активность обусловлена эффектом взаимодействия кислорода с центральным ионом металла. Очевидно, в данном случае ион металла, взаимодействуя с кислородом на поверхности электрода, оказывает каталитическое влияние на данный процесс. Об эффекте взаимодействия и каталитическом влиянии говорит и сдвиг потенциала волны электровосстановления кислорода в отрицательную область при добавлении образцов в раствор.

Установлено, что антиоксидантная активность гуминовых кислот в процессе хранения увеличивается. Анализ результатов показал, что антиоксидантная активность всех образцов увеличивается в 2 раза, за исключением образцов ГК-2 и ГК-3, результаты которых увеличиваются в 1,5 раза.

Установлено, что антиоксидантная активность фульвокислот в процессе хранения увеличивается. Анализ результатов показал, что антиоксидантная активность всех образцов увеличивается в 2 раза, за исключением образца ФК-1. Здесь произошло увеличение в 2,5 раза.

Анализируя изменения антиоксидантной активности ГК и ФК в процессе хранения, можно предположить, что происходит высвобождение активных центров, которые начинают более активно реагировать с кислородом и его радикалами, это мы замечаем в эксперименте как повышение антиоксидантной активности.

Таким образом, в результате эксперимента было выявлено увеличение антиоксидантной активности гуминовых и фульвокислот в процессе хранения, что позволяет сделать вывод о возможности использования гуминовых и фульвокислот при длительном хранении.

При более длительном хранении и последующем окислении активных центров ГК и ФК возможно снижение антиоксидантной активности, 


\section{Список литературы}

1. Мозгов Н.Е. Стимуляторы роста животных. М., 1960. 254 с.

2. Четвериков Г.Н., Базанов Г.А. Действие препаратов торфа на поведение и выживаемость животных в экстремальных условиях // Применение торфа в народном хозяйстве : межвузовский тематический сборник. Калинин, 1982. С. 15-19.

3. Маякова Е.Ф., Манжола А.П., Иссат Т.Г. Торф - нетрадиционное сырье для производства кормовых продуктов животноводству // Труды Всесоюзного научно-исследовательского института торфяной промышленности. 1983. Вып. 51. С. 110-113.

4. Удинцев С.Н., Жилякова Т.П. Применение кормовой добавки Гумитон в перитональный период у высокодойных коров // Инновационные аспекты добычи, переработки и применения торфа : материалы международной конференции. Томск, 2011. С. 142-146.

5. Лиштван И.И., Король Н.Т. Основные свойства торфа и методы их определения. Минск, 1975. 320 с.

6. Короткова Е.И. Вольтамперометрический метод определения суммарной активности антиоксидантов в объектах искусственного и природного происхождения: дисс. ... доктора хим. наук. Томск, 2009. 382 с.

Поступило в редакичию 29 января 2013 г.

Maslov S.G. , Kusmaul S.A., Korotkova E.I., Voronova O.A. AN ANTIOXIDANT ACTIVITY OF HUMIC AND FUIVIC ACIDS CHANCHE DURING THEIR STORAGE

National Research Tomsk Polytechnic University, Lenina ave., 30, Tomsk, 634050 (Russia), e-mail:maslovsg@tpu.ru

Cathodic voltammetry was used for determination of antioxidant activity of two peat types with different decomposition rate. It is shown that the antioxidant activity increased during storage for a year.

Keywords: peat, humic acids, fulvic acids, storage, antioxidant activity, change.

\section{References}

1. Mozgov N.E. Stimuliatory rosta zhivotnykh. [Animal growth promoters]. Moscow, 1960, 254 p. (in Russ.).

2. Chetverikov G.N., Bazanov G.A. Primenenie torfa v narodnom khoziaistve: mezhvuzovskii tematicheskii sbornik. [Application of peat in the national economy: Interuniversity thematic collection]. Kalinin, 1982, pp. 15-19. (in Russ.).

3. Maiakova E.F., Manzhola A.P., Issat T.G. Trudy Vsesoiuznogo nauchno-issledovatel'skogo instituta torfianoi promyshlennosti. [Proceedings of the All-Union Scientific Research Institute of peat industry]. 1983, no. 51, pp. 110113. (in Russ.).

4. Udintsev S.N., Zhiliakova T.P. Innovatsionnye aspekty dobychi, pererabotki i primeneniia torfa: materialy mezhdunarodnoi konferentsii. [Innovative aspects of the production, processing and application of peat: Proceedings of the International Conference]. Tomsk, 2011, pp. 142-146. (in Russ.).

5. Lishtvan I.I., Korol' N.T. Osnovnye svoistva torfa $i$ metody ikh opredeleniia. [Basic properties of peat and methods for their determination.]. Minsk, 1975, 320 p. (in Russ.).

6. Korotkova E.I. Vol'tamperometricheskii metod opredeleniia summarnoi aktivnosti antioksidantov $v$ ob"ektakh iskusstvennogo i prirodnogo proiskhozhdeniia: diss. ... doktora khim. nauk. [Voltammetric method for determination of total antioxidant activity in objects-vennogo artificial and natural origin: the dissertation of the doctor of chemical sciences]. Tomsk, 2009, 382 p. (in Russ.).

\footnotetext{
* Corresponding author.
} 
